\title{
Analysis of the Development of University Entrepreneurship Education Against the Background of Electronic Commerce
}

\author{
Yingbin Chen \\ Institute of Public Administration \\ South China University of Technology \\ Guangzhou, China
}

\begin{abstract}
In order to meet the call of the times of "mass entrepreneurship and mass innovation", in recent years, colleges and universities in our country have carried out a series of new attempts in the development of entrepreneurship education. However, under the background of the vigorous development of electronic commerce, the related entrepreneurship education in this field obviously fails to meet the development requirements of the times, the overall development level is generally not high, and the orientation of e-commerce entrepreneurship education is not clear. There are many problems such as lack of entrepreneurial atmosphere, lack of appropriate guidance and so on. In view of this, the author will discuss the theme of entrepreneurship education development under the background of e-commerce in colleges and universities from the aspects of autonomous learning, guided teaching, and platform practice and so on.
\end{abstract}

Keywords-entrepreneur education; electronic commerce; pratical experience

\section{INTRODUCTION}

Since Premier Li Keqiang first put forward the concept of "mass entrepreneurship, mass innovation" in 2014, there has been a new wave of innovation and grassroots entrepreneurship in the society. In recent years, with the joint efforts of multiple subjects, including the government, society and educational institutions, entrepreneurship education in colleges and universities has been strengthened and made positive progress, but this is still far from enough, because entrepreneurship education in China started relatively late. There are some subjective and objective reasons, such as the deviation of entrepreneurship concept, the mismatch between the ecological environment of entrepreneurship and the needs of reality, which lead to a lot of bottleneck problems in the development of entrepreneurship education in our country.

With the continuous development of economy and science and technology, e-commerce has been widely concerned by the outside world because of its low cost and high profit business model. In 2013, the scale of e-commerce transactions in China broke through the 10 trillion mark, and a total of 9.62 million people were directly employed in online stores nationwide. Indirect employment exceeds 1.2 million, becoming a new growth point of entrepreneurial employment. [1] For those college students who want to achieve their own employment and self-worth through entrepreneurship, this will undoubtedly be an extremely effective way. But at present, the domestic research on this field is less, lack of good experience can be popularized, resulting in the development of entrepreneurship education under the background of e-commerce has not kept pace with the pace of development of the times.

\section{PROBLEMS IN ENTREPRENEURSHIP EDUCATION IN ELECTRONIC COMMERCE}

\section{A. The Orientation of E-commerce Entrepreneurship Education Is Unclear}

With the continuous promotion of mass innovation and mass entrepreneurship, the development and construction of entrepreneurship education in colleges and universities in our country has made great achievements. However, in the context of e-commerce, there are still many vague understandings and details to be considered. E-commerce is a complex subject involving knowledge of economics, computer technology, marketing, etc. [2] its talent training needs are also diversified, and its orientation is applied talent (with the ability of trade operation, management and control, etc.), Elite talent (with sharp market insight and decisionmaking ability), and even international talent (knowledge of transnational culture, knowledge of the international frontier theory and skills, etc.). But few colleges and universities can make a clear and profound orientation to it, the phenomenon of mere formality is more common, so there has not been found a more suitable way of development on the related entrepreneurship education mode: the curriculum is single, Most of the traditional classroom education, the practice guidance is less; the two-teacher system cannot be implemented effectively, most of the entrepreneurial mentor is the administrative teacher, the practice guidance ability is generally not high. 


\section{B. Lack of Appropriate Guidance for Entrepreneurship in Schools, Entrepreneurial Climate Is Still Not Strong}

The guidance of entrepreneurship in colleges and universities is not only limited to classroom education, but also needs to focus on cultivating an atmosphere in which everyone can innovate and start a business, to guide students to develop innovative entrepreneurial thinking, and to respond to the timely proposal by the Party and the state of "mass entrepreneurship," the call for innovation. At present, most colleges and universities only rely on classroom teaching and entrepreneurial incubating base to try to promote entrepreneurship education, but this can only promote the development of students from the surface, so universities must affect the development of students and entrepreneurial teams from a more in-depth perspective. Throughout the foreign universities such as Stanford University, attach great importance to the cultivation of campus entrepreneurial atmosphere, encourage students to learn independently after class, in the corner of the campus to set up after-school entrepreneurship discussion and exchange angle, so that the spring breeze of entrepreneurship haunts every corner of the campus. [3] At the same time, we also vigorously support the entrepreneurial students' organizations such as creation, starting with student associations, and imperceptibly infiltrate the thinking of innovative entrepreneurship into the students' groups. If the school fails to provide effective guidance, such as providing a suitable platform for entrepreneurial exchange, perfect educational facilities, will greatly reduce the enthusiasm of students to carry out relevant knowledge learning, participation and entrepreneurial success rate.

\section{Relevant Supporting Mechanisms for Entrepreneurship Practice Are Not Yet Sound}

Most colleges and universities have not yet formed a sound set of entrepreneurial practice supporting mechanism, especially in e-commerce. For the e-commerce industry relies heavily on platform development, but there are few colleges and universities that can provide students with the most basic platform for practice opportunities, so students can only learn the theories. Never have they had a chance to experience the real battle in business. This phenomenon of insufficient support has not only caused the high threshold of e-commerce entrepreneurship in schools, which has deterred students with entrepreneurial ideas, but also failed to enable students to exercise their ability to avoid risks and improve their ability to make decisions in practice as early as possible. This greatly reduces the success rate of independent entrepreneurship.

At the same time, the contribution of colleges and universities in improving the profitability of student group entrepreneurship is slightly inadequate. For example, on the pre-venture start-up fund matching mechanism, most colleges and universities have failed to establish a cooperative and reciprocal model with large platforms at home and abroad, such as Alibaba and Amazon, nor have they set up a pool of venture funds to support students' entrepreneurial practice. This leads to a higher threshold to start, which also limits the vigorous development of the school e-commerce entrepreneurship team; for example, there is a lack of systematic measures to help the entrepreneurial team to achieve profit increase, improve the entrepreneurial technology content and online service level.

\section{EXPLORING THE PATH OF ENTREPRENEURSHIP EDUCATION UNDER THE BACKGROUND OF ELECTRONIC COMMERCE}

\section{A. Promote Autonomous Learning and Improve Students' Level of Self-employment in an All-round Way}

Colleges and universities should draw lessons from the inspiration of constructivism and develop entrepreneurship education in colleges and universities. According to this theory, knowledge is not imparted by teachers, but by the help of other people (including teachers and learning partners) in a certain context, i.e. in the context of sociocultural background, using the necessary learning materials, through the way of meaning construction to obtain. [4]Therefore, colleges and universities should fully mobilize students' consciousness of autonomous learning, give play to students' subjective initiative, focus on autonomous learning, and cultivate their strong interest in learning.

In the process of autonomous learning, teachers should guide students to study creatively. That is, in the process of knowledge integration and construction, we can carry out inquiry learning independently, including a series of activities including observing, proposing, solving and so on. At the same time, group learning should be carried out to make full use of the interaction between the various factors within the team system to promote the efficiency of learning. For example, colleges and universities can provide a platform for students to set up e-commerce entrepreneurship teams, carry out group learning and even group entrepreneurial practices, and be equipped with a mentor in and out of school.

At present, many colleges and universities in China also have to carry out entrepreneurship classes to give full support to students with independent learning consciousness. For example, the students can volunteer to enroll in entrepreneurship clinics, new media marketing training camp and other projects training. The author has participated in the project management training camp. The course has invited experts from the PMP Global Test Bank and special project management lecturer at Tsinghua University to give a lecture. The course form is different from that in the ordinary classroom, taking lectures, real case studies and production, simulation road shows, etc. During the training period, the intensity is very high, the classroom atmosphere is relaxed and pleasant, and is well received by the students. [5] Colleges and universities can also launch MOOC online micro-course of e-commerce entrepreneurship at the right time to meet the needs of students studying anytime and anywhere. 
B. Pay Attention to Guiding Teaching, Promote Innovation by Competition, at the Same Time Give Play to the Role of Community Guidance

In recent years, various kinds of e-commerce entrepreneurship competition emerge in endlessly, mostly through the business competition to screen out the outstanding team to support and incubate the entrepreneurship. Colleges and universities should grasp this opportunity and encourage students to participate in the way of entrepreneurship competition under the guidance, to learn the theory of knowledge in practice. At the same time, this university can also take this opportunity to test its own effective degree of implementation of entrepreneurship education, constantly carry out its own reform and development; inspect the students' ability to connect theory with practice, solve problems, find talents, cultivate talents. Encourage students to participate in the challenge cup, Internet + entrepreneurship competition, and arrange for entrepreneurship mentors to follow up later cultivation, analyze their business canvas, promote the transformation of business results, and create a vibrant entrepreneurial culture atmosphere in the school. At present, the level of innovative entrepreneurship education in China is uneven, in addition to the different levels of education in colleges and universities, but also with the economic development of various regions, industrial characteristics. Therefore, colleges and universities should vigorously promote innovative entrepreneurship education, at the same time, should understand the actual needs of economic development in various regions, integrate their own disciplinary advantages, and carry out mutually beneficial innovation and entrepreneurship development model.

Colleges and universities can also improve the impact of competition to promote innovation through their entrepreneurial parks and incubating bases, guide and support students to participate in large-scale entrepreneurial competitions and incubate award winning teams. Qualified colleges and universities can also cooperate with the benchmark enterprises in the e-commerce industry such as Alibaba, Amazon, VIPSHOP, and sign relevant industrystudy-research cooperation agreements. Colleges and universities can send outstanding projects and talents to enterprises. The enterprise also helps incubate team to realize the win-win situation of the cooperation between industry, university and research. In addition to providing office space for entrepreneurial students, the campus incubator base can also lead students to the market, more skillfully deal with such activities as commercial negotiation of products, and provide value-added services for students to start their own businesses. Only by enriching the functions of incubator base, such as business registration, tax service, expert guidance, project bidding, and venture capital roadshow and so on, can we really help students to solve the actual problems and create a good reputation of entrepreneurial park. Promote the spread of entrepreneurship on campus.

In addition, colleges and universities should also pay attention to the additional entrepreneurial culture construction functions of the community, such as creating a team Enactus student association committed to commercial thinking to do the public good, but also encourage students to share the results of team entrepreneurship to help the object, In order to solve social problems, including site inspection, in-depth study of social issues, personal participation in project development. For example, the recent "Xiangxi Series" focused on urban development and helped sell unsalable bacon and rice in the form of electronic commerce in the remote rural areas of Xiangxi. And try to explore a suitable for the development of rural China's economic development of electronic commerce can be popularized way.

\section{Develop Platform Practices to Provide Opportunities for E-commerce Entrepreneurship}

At present, most colleges and universities in China are trying to build a platform base of entrepreneurial practice based on multi-party cooperation. However, due to the limitations of regional, financial and policy conditions, many incubating bases and creating space have not reached the expected goal. The general problem lies in the failure to provide an opportunity to practice on a flat platform. Students are mostly talking on paper and fail to understand the real experience of real life in business.

Compared with other real economic entrepreneurship, ecommerce is most unique in its dependence on trading platforms. Therefore, colleges and universities should take the lead with major online e-commerce platforms such as Alibaba, Amazon, Taobao and so on, to provide entrepreneurs with a real business e-commerce practice platform, and a series of preferential policies. To provide training and guidance services for e-commerce entrepreneurship projects. Through this type of practice platform, students can devote themselves to the practice of electronic commerce. In the practice of pre-project development, medium-term marketing promotion, postfeedback optimization, so that students can better adapt to the needs of their jobs. And they can obtain a higher starting point for career development, to lay a better foundation for the future career development. I am also engaged in ecommerce entrepreneurship, so in the process of practice has a more profound experience. Colleges and universities can sign mutual aid agreements with e-commerce enterprises such as Ali, JingDong and Taobao, and send a large number of interns or regular staff to the company every year. The actual combat scene can make students adapt to the needs of their jobs and seek a faster career development path

On the one hand, we can develop domestic e-commerce entrepreneurship practice camps for the domestic ecommerce market, screen eligible entrepreneurs through competitions and other forms, taking root in Taobao platform, and carry out a full set of e-commerce entrepreneurship training, including the transaction page optimization art, upstream source screening and medium-term supply chain management, later marketing promotion planning and so on. Through the training and assessment of the college can be on the job practice, Taobao Company regularly with the students funded to open a shop to communicate, control the direction of the development of the store. This model can not only cultivate students' interest in e-commerce 
entrepreneurship, but also cultivate Internet thinking. It can also improve the success rate of entrepreneurship, realize the profit increase of the team and enterprise, strengthen the students' confidence in starting a business independently, and form a virtuous circle. Only by enriching the functions of incubator base, such as business registration, tax service, expert guidance, project bidding, and venture capital roadshow and so on, can we really help students to solve the problem of profitability. So that entrepreneurial parks, incubators can become a high-end industry with the characteristics of the times. It is necessary for colleges and universities in our country to provide long-term financial support to the entrepreneurial team on campus, set up the venture capital in the school, attract the venture capital team from the pool of teachers to come back to look for investment objects, and provide help for the follow-up management consultation of the entrepreneurial team.

Second, colleges and universities can look to the more competitive international market, establish cooperative relations with cross-border trade platforms such as Amazon and EBay, and establish international e-commerce entrepreneurship camps, so that students can truly contact international trade practices. Improve the students' practical ability and competitive ability, so that they can become entrepreneurial talents with keen insight in the international market. In recent years, cross-border e-commerce has become a new growth point in e-commerce industry. According to statistics, since 2014, China's customs crossborder e-commerce imports and exports an annual increase of more than 50\%. [6] Different from domestic e-commerce entrepreneurship, cross-border foreign trade has greater competitive risks and higher requirements for entrepreneurial students, involving differences in transnational culture, consumer psychology and access mechanisms for goods. Faced with such complicated knowledge structure, it is difficult to carry out systematic and effective learning by individual students alone. Therefore, colleges and enterprises need more comprehensive practical guidance for students, not just to impart good cultural and theoretical knowledge. It is necessary to enhance professional skills such as market insight, product development, data processing, and marketing and promotion capabilities.

\section{CONCLUSION}

It is true that China's e-commerce entrepreneurship education still faces a lot of obstacles, in addition to more clear guidance and positioning in the superstructure, we also need to start from the perspective of independent learning, guided teaching and platform practice. Further enhance the overall level of students to improve their own entrepreneurship, to promote innovation, at the same time, play a leading role in the community, to provide e-commerce entrepreneurial opportunities.

\section{REFERENCES}

[1] Analyse: the development of electronic commerce in china in this twenty http://www.ec.com.cn/article/dsyj/yjsd/201609/11881_1.html
[2] Wei Hao, the role of practice teaching in electronic commerce major in college, Eletronic commerce, 2012

[3] Shi Guanqun, Liu Linqin, Chen Xiaoxia, the network building of entrepreneurship education and entrepreneurship college, take Standford university as an example, Studies in Foreign Education, 2009.

[4] Zhu Xiaomei, Li Yane, Zhang Jingfeng, Zhang Rui, The reaserch on the major education and entrepreneurship education, based on the constructivism theory, Journal of Shanghai University of International Business and Economics, 2016.

[5] The report of startups development promotion of colleges: south of china ranks the first, http://www.edu.cn/xxh/xy/xytp/201704/t20170418_1507717.shtml

[6] Electronic commerce is entering the revelution era, and Guangdong is facing to new opportun, http://www.ec.com.cn/article/qyds/gd/201803/26833_1.html 1 